\title{
Benefits of Music Intervention for Students with Autism Spectrum Disorder
}

\author{
Finn Haftinga ${ }^{\mathrm{a}}$ Birdie Bezanson ${ }^{\mathrm{b}}$
}

Current literature, (Gold, Wigram, \& Elefant, 2006), (Wimpory \& Chadwick, 1995), (NRC, 2001), suggests that there is insufficient evidence to predict long-term ( $\mathrm{P}$ to Grade 12) benefits of music intervention for students with Autism Spectrum Disorder (ASD). To understand how music intervention can be employed in Nova Scotian schools, music teachers, music therapists, and staff of the Nova Scotia Department of Education and Early Childhood Development were interviewed. The primary needs of students with ASD were identified as, Expression of thoughts, Language, Motor skills, and Social skills. Music intervention was found to have substantial long-term and short-term benefits for students in all grade levels depending on their individual needs. However, to treat these needs, elements of music and music intervention must be considered during program planning meetings.

Keywords: Interview Coding; Music Intervention; Autism Spectrum Disorder; Nova Scotia

Over the past couple decades, music therapy has become more of a medical practice as more research begins to emerge, this has changed the perspective of music as it can now be viewed as a tool (Whipple, 2004).

Music therapy is defined as "a form of psychotherapeutic treatment where the therapeutic relationship is used to decrease psychic problems, conflicts, and disturbances of the client" (Krikeli et al., 2010). Krikeli et al. discovered that music therapy significantly decreases heart rate and state anxiety for children with Autism Spectrum Disorder (ASD). This study shows that research has investigated initial benefits of early music intervention strategies, however little is known about how these benefits stand over time.

Social and communication skills are the most significant struggle for students with ASD (Gold, Wigram, \& Elefant, 2006). Wimpory \& Chadwick (1995) found that music interaction therapy, another music intervention strategy, was a helpful tool for the development of social skills in a 3-year-old child. Results show that the therapy had a significant and positive impact on the child's social interaction and imagination skills, 20 months later it was confirmed that these changes had been sustained over two years. However, there were many unaccounted factors in the child's life that may have, in some way, affected the results of the experiment. This study also only considers the impacts of one individual.

Other investigation showed that music therapy had significantly improved an 8-year-old child's social skills (NRC, 2001). This source, Assessing Change in Early Intervention Programs for Children with Autism, suggests that in order for the child to see the largest impact, music therapy should incorporate aspects into the child's life, such as involving their parents. Upon assessment of various intervention strategies, it was concluded that children with ASD who are 8 years or younger could see benefits such as improved social skills, motor skills, behavior (i.e. reduction of tantrums), and improved symbolic communication skills (i.e., reading and writing). However, these results vary based on the type of person, and the goals of therapy may change as the child gets older.

Another study (Srinivasan \& Bhat, 2013) identified that the improvement of gross and fine motor skills could be a product of music intervention as a result of synchronizing the arm and body movement with the rhythm of a song. This can be further developed through instrument playing.

These studies propose similar arguments when it comes to further research. Little is known about the impacts of long-term music intervention strategies (i.e., over years), as opposed to the body of knowledge already surrounding early intervention (i.e., over months). It was also determined that the benefits of music intervention for children with ASD can be arranged into five categories: social interaction, confidence, behavior, language, and motor skills. Current literature is primarily focused on the behavior, social interaction, and communication skills that can be developed through music intervention (Accordino, Comer, \& Heller, 2007).

\section{Literature Review}

\section{Social Interaction}

A large problem that students with ASD face is their inability to understand someone else's emotions (Frith, 2001). By using the Empathizing-Systemizing Theory Greenberg et al. (2015) reviewed many articles to look for trends on how music could influence someone's "mindfulness", such as their ability to notice patterns in someone's body language. Empathizing-Systemizing Theory states that empathizing is the drive to understand the behavior of agents (usually people) by inferring their mental states, where systemizing is the drive to predict the outcome of something by assessing the possible ways to create that outcome (Greenberg et al., 2015). The framework of this theory helps explain the basis of many social problems faced by children with ASD. The authors concluded that music can be used to decrease cultural boundaries and increase prosocial behavior, thus developing an understanding of equality and mentality towards others. This was also supported by Finnigan \& Starr (2010) who found that music intervention obtained the highest frequency of social engagement.

a. Annapolis West Education Centre, Nova Scotia, Canada, B0S1A0

b. Acadia University, Nova Scotia, Canada, B4P2R6 


\section{Confidence}

Music therapy sessions are used as a way for a child with ASD to develop the skills needed for them to function independently. However, the goals of these sessions are often difficult to reach due to the child's lack of confidence. While the primary goal of music therapy may not be to improve a child's self-image and esteem, often this is a byproduct of being involved in music intervention activities.

By using music education, Kern, Wolery, \& Aldridge (2007) were able to improve the confidence of two, 3-year-old boys with ASD. Their study involved the incorporation of music during the class's morning greeting routines and assessed the number of times the child was able to complete the steps on their own. Both boys showed significant increases in the amount of independent steps completed, however one child's results were less consistent. Some limitations of this study may have caused this outcome. Because it was noticed that the child became distressed during intervention a modification needed to be made. It may seem like these results cannot be compared for this reason, however the NRC report (2001) suggested that music therapy strategies will need to be different for various people in order for the person to improve. Under these circumstances, benefits experienced by both children are still significant.

Another intervention strategy called "Behavioral Momentum" has the student first accomplish tasks which are simple and, after building up their confidence, introduces a new element to engage the student in their area where they need development. The notion of behavioral momentum is that a behavior will persist following a change in environmental conditions. By building up their confidence they feel more capable of performing the task than before (Mace et al., 1988).

\section{Behavior}

Behavior is an important factor that encompasses the social and confidence aspects involved in a child's development. Sallows \& Graupner (2005) suggest that a child should go on regular play dates in order to develop behavioral skills and imagination. By looking at multiple cases of students involved in music therapy, Pelayo and Sanchez (2013) determined that behavioral improvements significantly change in children and youth with ASD ages 4-18. A recurring trend was prominent in their assessment, with frequent tantrums and stubbornness being almost always corrected by the end of the sessions. This was interesting because these negative behaviors were also the most prominent factors that needed to be fixed during the beginning stages of therapy.

When a child is around 9 months old, they develop a behavioral response called joint attention which helps them develop language skills from their parents (Kim, Wigram, \& Gold, 2008). This can be adapted through improvisation music therapy allowing students to explore new forms of expression and communication (Tomasello \& Farrar, 1986).

A dissertation written by John Yeaw (2001) found that the impacts of music therapy on behavior were impacted by two factors, affect identification and mood induction. Affect identification demonstrated how children could identify an affective quality in music such as emotion. Mood induction showed how music could exert an emotional response in children. Both factors were responsible for the behavioral changes seen in children with ASD.

\section{Language}

Sallows and Graupner (2005) studied the effect of music on language development by exploring how two types of music therapy can affect the language IQ of 24 individuals with ASD. The treatment lasted four years and involved children ages 3-8. The results of this study show that increased language IQ was dependent on the child and not the treatment. $48 \%$ of the children showed rapid learning and a greatly increased language IQ, however, these children already had an initial language IQ of 55. These findings reflect previous literature, (NRC, 2001), (Kern, Wolery, \& Aldridge, 2007), which suggested that music therapy must act in accordance with the individual's own strengths and weaknesses in order to result in significant benefits.

\section{Motor Skills}

Motor skills improvement can be accomplished through learning to play an instrument or through "rhythmic entrainment" (Orr, Myles, \& Carlson, 1998). Rhythmic entrainment happens when one's mind becomes "locked" into the rhythm of a song. As a result, subconscious muscle movement is exhibited, such as foot tapping or head bobbing. This study found that rhythmic entrainment had a large effect on a girl with ASD, aged 11. They were able to treat behavioral issues by using rhythm, however, the results that were seen may have been caused by outside interferences such as anxiety or the child's daily life at home. Another study identified music education as a good source for treating fine motor functions (Srinivasan \& Bhat, 2013). The authors found that through instrument playing a student could develop fine motor skills when learning a song.

After exploring the efficacy of various music intervention strategies, Kasari (2000) found that different treatments could provide separate benefits. It was determined, ten years after intervention, that music therapy provided substantial long-term benefits for children with ASD. However, more information needs to be gathered to determine how this relates to students with ASD in Nova Scotia.

To explore long-term music benefits, this paper investigates the following question: what are the perceived benefits of a music education program specifically from P-12 for students with ASD in Nova Scotia? Based on the reviewed literature it can be hypothesized that music intervention may provide significant benefits for all grade levels, however, this may be dependent on the student's previous ability and willingness to learn.

\section{Methods}

\section{Participants}


Three groups were interviewed in order to evaluate multiple perspectives in regards to the perceived benefits of music intervention for students with ASD from P-12. These three groups were music teachers throughout Nova Scotia, staff from the Department of Education and Early Childhood Development of Nova Scotia (DoEECD), and music therapists who treat people with ASD. Participants were selected based on their experience with students who have ASD, and if they were based in Nova Scotia. Individuals were interviewed over the phone, using structured interview questions. Each group received a different set of questions pertaining to their area of expertise. This was to ensure that, while relationships can still be found among interviews, unique answers are also obtained. Each participant was asked if they would like to remain anonymous. This method is similar to Pelayo \& Sanchez (2013).

\section{Music Teachers}

Interviews involving music teachers discussed the impacts that a music program has had on students such as the growth they had seen, how music impacted the student's school life, and why the student enjoyed the program. Middle school and High school music teachers were interviewed. Data from the autism consultant for the DoEECD discussed the early childhood benefits in elementary schools.

\section{Staff of the DoEECD}

To understand what factors should be considered when planning a music education program, two members of staff from the DoEECD were interviewed: the autism consultant and the arts consultant. These interviews discussed the perceived benefits of music education for students with ASD, however they dove deeper into the factors that should be considered in order for a music program to be successful.

\section{Music Therapists}

Music therapy and music education share similar strategies, because of this music therapists were interviewed to understand the benefits of music therapy for students with ASD. Specifically, they were asked how their music therapy programs have impacted individuals with ASD in the past and how this could relate to music education programs. The music therapists in question specialized in treating people with ASD as children and young adults. Four people were interviewed in this group.

\section{Data Analysis}

To systematically understand relationships among the interview data, a coding strategy was employed which analyzed interview transcripts to look for keywords or phrases that related to each other. These codes were used to organize data as well as find key themes among the interviews which could relate to one another. Benefits were organized into a histogram which shows the percent of participants who identified a certain benefit. Codes were organized into a chart in order to show how elements of music, music therapy, and music education relate to the needs of students with ASD.

\section{Results}

Upon analysis using a coding strategy, it was determined that the needs of students with ASD could be divided into four groups: Social skills, Motor skills, Language, and Expression of thoughts (Figure 1). These four categories originated from keywords and phrases in the interview transcripts which shared similar transcription codes. Figure 1 shows how these concepts are related based on the elements of music, music therapy, and music education. Music was divided into three main elements all of which connect to the needs of students with autism. Music allows for expression, has an element of predictability, and has rhythm.

Elements of music therapy were divided into two main categories. Therapy develops around the student's individual needs, and it focuses on the process of learning. The factor of individual learning was further divided into some of the main therapeutic strategies, including improvisation, songwriting, music listening, singing, and instrument playing (Figure 1). These were all connected to the needs of students, excluding the 'Social skills' needs, with most of the relationships connecting to 'Language'. 'Focuses on the process of learning' was related to forming a connection with the therapist (one of the main goals of therapy) which related to the 'Individual connection' element of 'Social skills' needs (Figure 1).

Music education was divided into two main categories: focusing on teaching and allowing the development of social skills. The teaching aspect was divided further into 'Music language and theory', which relates to 'Language', and 'Learning an instrument', all of which relates to 'Motor skills'. The development of social skills was divided into socializing in the band which relates to the community element of 'Social skills' needs, and allowing other students to understand autism with relates to the 'Empathy' element of 'Social skills' needs.

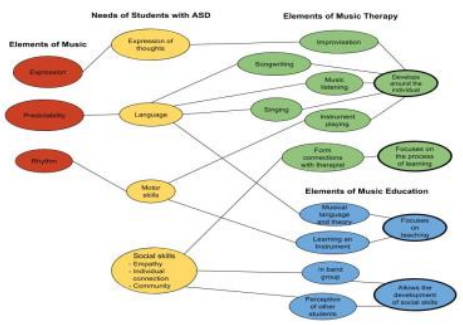

Figure 1. Elements of Music and ASD. This figure illustrates relationships between student's needs and intervention strategies 


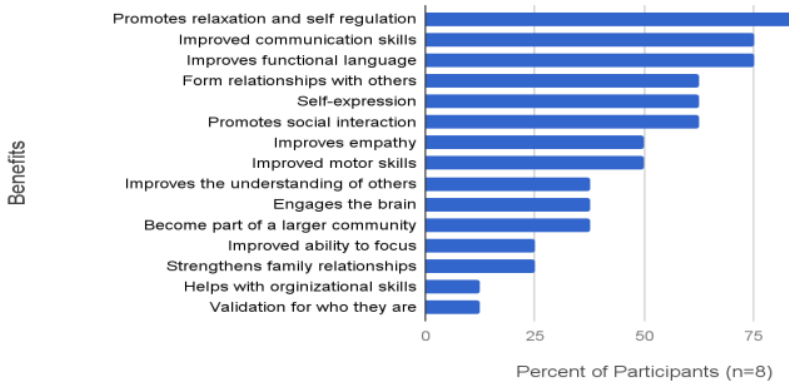

Figure 2. Percentage of Benefits Discussed. This graph shows the percentage of people who identified a certain benefit of music intervention.

Main benefits were arranged into a histogram in order to identify benefits that were discussed most often (Figure 2). 'Improved communication skills', 'Form relationships with others', 'Promotes social interaction', and 'Improves empathy' were all above $50 \%$ and all relate to the 'Social skills' needs of students with ASD (Figure 1). 'Promotes relaxation and self-regulation' was the most discussed benefit with $7(\mathrm{n}=8)$ participants $(87.5 \%)$ identifying this as a benefit. 'Improved functional language', 'Selfexpression', and 'Motor skills' were all identified by at least $50 \%$ of respondents. These three benefits directly relate to the 'Expression of thoughts', 'Language', and 'Motor skills' needs of students with ASD (Figure 1).

\section{Discussion}

Current research, (Gold, Wigram, \& Elefant, 2006), (Wimpory \& Chadwick, 1995), (NRC, 2001), suggests that there is insufficient evidence to conclude whether music intervention has long-term benefits which could be assessed through music education. It was identified during every interview that the needs of students with ASD are unique and specific, and will change with time. Often a student may need more time for development in which case a long-term intervention program would be beneficial. However other students will have different needs and may react differently to music. In this case, it is very difficult to say whether long-term intervention strategies are beneficial for all students with ASD.

Five categories can be revisited to discuss the needs and challenges of which students with ASD are faced. Revision of these categories shows that 'Expression of thoughts', 'Language', 'Motor skills', and 'Social skills' are the primary needs of these students (Figure 1). As shown in Figure 2, four of the top benefits discussed correlate to the social needs of students with ASD. This was most likely due to the complexity of the social element which was further divided into three main categories, 'Empathy', 'Individual connection', and 'Community'.

\section{Expression of Thoughts}

Many of the methods and studies, behavioral momentum and discrete trial-traditional behavioral (DT-TB), which look at the confidence and behavioral aspects of music intervention can be narrowed down into this single category. It was identified that many students with ASD can have trouble speaking, communicating, or being understood. Because of this, it was very important for students with ASD to explore other ways of expression and communication. A quote from interview participant Paul Lauzon, MTA and the professor of Music Therapy at Acadia University articulates this point well.

"When you're dealing with verbal issues, communication becomes so important. One of the benefits of music is that you can work out other ways of communication which don't involve speech. For example, I could use call and response in a song allowing the child to sing their response. This can help develop voice control, new vowel sounds, and pitch range."

The term "Nordoff Robbins" was also discussed which is an intervention strategy that uses musical improvisation. This aspect of music therapy was very important for the student's expression because it allows them to communicate without words. Music has the ability to elicit emotions which is what makes it so powerful. This can lead to subsequent language development, another crucial part of communication and expression.

\section{Language}

Like the expressive elements of music, language involves many of the same skills and strategies employed in improving communication with the therapist. Music is predictable which allows intervention strategies such as the use of "Fill-in" songs which start with singing and allow the student to fill in areas of the song. During interviews, the autism consultant for the DoEECD discussed the importance of this strategy. The student has to come up with something without any references, which involves using their imagination, something with which students with ASD may also struggle. An intervention strategy like this can lead to subsequent language development by helping the student practice communication in a conversation setting. The music teacher could ask a student what they had for dinner the night before, the student then responds without the use of any references, and thus a conversation is started. Interview participant Antonia Pigot, MT used fill-in songs to allow the student to express their feelings through words.

"A girl aged three had a similar issue of speech production. For her to communicate with words, we would sing a song about an instrument she wanted to play. She could only play the instrument if she said what it was called. Her parents talked to me later about how she could say xylophone but couldn't say Mommy or Daddy."

This girl had no prior language knowledge, but she was still able to pronounce complicated words through music, this speaks to the strength of music for children with ASD.

a. Annapolis West Education Centre, Nova Scotia, Canada, B0S1A0

b. Acadia University, Nova Scotia, Canada, B4P2R6 


\section{Motor Skills}

Rhythmic Entrainment is a term used to describe how music can lock a rhythm into the listener, evident with subconsciously foot tapping to the beat of a song. This characteristic of music is useful for treating students with ASD because it allows the therapist to either slow things down (relax) or speed things up (excite). To treat students with movement problems, a specialist could use rhythm to provide the student with an opportunity to improve coordination and sense of self. This strategy was also discussed with interview participant Antonia Pigot, MTA who explained how she used rhythm to treat a child with motor skill issues.

"I had a child aged four who didn't know how to jump. Using the rhythm of 'When the Ants Come Marching In' and by placing her feet on a large drum, she began to jump to the rhythm using the drum as the beat. We later went on to marching."

Students with ASD can have anxiety from their lack of communication skills, so using rhythm can be very useful as an intervention strategy for calming down the student.

Music education can also be helpful for motor skill development particularly by learning to play an instrument. Both music teachers interviewed said that being involved in the band can have an impact on motor skills and coordination. Similarly, this response was articulated by some music therapists who use instrument playing as an intervention strategy. Motor skills were discussed by $50 \%$ of participants.

\section{Social Skills}

The most influential impact music can have on students with ASD is the social element. 'Social skills' can be divided into three groups 'Empathy', 'Individual connection', and 'Community' (Figure 1).

Empathy is based on the individual student's understanding of social interaction; however, it can also involve the understanding of their peers and fellow classmates. Music, having the ability to allow for expression and communication, has given students with ASD another way of expressing themselves and subsequently other students learn to empathize with them. While this empathizing of other students was only discussed by 3 people $(n=8)$ it is the product of language development and improved communication skills.

'Individual connection' was discussed by all music therapists who were interviewed, however, this was part of 'Promotes social interaction' because most of the strategies used to create this connection are also intended to improve the child's communication and language skills. Participant Anna Plaskett, MTA, explained how she does many of her sessions within the student's household. This is what allows parents to connect with their child which is important for early development, and it also allows the therapist to diagnose and assess the student in order to design goals, and plan sessions to benefit the student. Because these goals can be different for everyone, it is crucial that this assessment is successful.

'Community' is perhaps where music education has precedence over music therapy. Within music education, students can participate in the school band which allows them to connect with their peers. Because music therapy is so individualized, the student does not get much chance to socialize. One music teacher who was interviewed explained how students with ASD can be reclusive because social interaction can be a daunting task. However, through the group dynamic formed in the band, the student gets to make friends that they might otherwise never have met based on their personality through school.

\section{Limitations}

The method utilized only explored the perceived benefits of music intervention in Nova Scotia, because of this, sufficient conclusions can only be made within this region. Also, while both music teachers saw great developments in high school students, this may have been because they were not exposed to music intervention in their developmental years of childhood. More people could have been interviewed, specifically music teachers and DoEECD staff. Because $50 \%$ of the participants were music therapists this may have added some bias to the results.

\section{Other Implications and Areas for Further Inquiry}

The impact that music has on students with ASD can be compiled into two primary themes, intraspecific and interspecific. Intraspecific refers to the elements of music itself that provide benefits to three of the student's primary needs, however, this doesn't address the social need (Figure 1). Interspecific refers to the music intervention strategies that use the elements of music, but also involve the experience of the therapist or teacher. Because music itself can't teach a child communication or social skills the involvement of specialists is required to see these benefits. Therefore, both intraspecific and interspecific factors must be considered when designing a program that addresses the needs of students with ASD.

Further studies could look at how these factors influence students with ASD, both intraspecific and interspecific. The needs of students with ASD will change as they become older so perhaps these factors will also change. Extending from school, other studies could research how adults with ASD benefit from these intervention strategies, what their needs are, and if these factors should be considered. Music intervention isn't the only way in which to treat students, perhaps other studies could also look at what other treatments offer.

\section{Implications for Potential Policy Changes}

A music education program can have all of the benefits listed in Figure 2, however, this is dependent on the factors that are considered during the program planning process. The data gathered shows how program planning meetings should be undertaken and identifies traits and needs that should be addressed specifically for students with ASD. The program planning process outlines that teachers should have an accurate understanding of the student's strengths and needs, and they should ask for information and advice from parents and other professionals (Nova Scotia Department of Education and Early Childhood Development, 2016). 
Similarly, it was proposed during interviews that the teacher should be aware of the general needs and symptoms of students with ASD, as well as student's individual needs, strengths, and interests. Involving music therapists in the school program can allow teachers to better understand a certain diagnosis, and then be able to treat the student by the best possible means. Strategies other than music therapy are used for students with developmental disabilities, however based on gathered interview data, this is the best way for students with ASD to be treated through a music intervention strategy.

\section{References}

Accordino, R., Comer, R., \& Heller, W. B. (2007). Searching for music's potential: A critical examination of research on music therapy with individuals with autism. Research in Autism Spectrum Disorders, 1(1), 101-115.

Basit, T. (2003). Manual or electronic? The role of coding in qualitative data analysis. Educational research, 45(2), $143-154$.

Finnigan, E., \& Starr, E. (2010). Increasing social responsiveness in a child with autism: A comparison of music and non-music interventions. Autism, 14(4), 321-348.

Frith, U. (2001). Mind blindness and the brain in autism. Neuron, 32(6), 969-979.

Gold, C., Wigram, T., \& Elefant, C. (2006). Music therapy for autistic spectrum disorder. Cochrane Database Syst Rev, 2.

Greenberg, D. M. (2015). Can music increase empathy? Interpreting musical experience through the empathizing-systemizing (ES) theory: Implications for autism. Empirical Musicology Review, 10(1-2), 80-95.

Kasari, C. (2000) Assessing Change in Early Intervention Programs for Children with Autism. Paper presented at the Second Workshop of the Committee on Educational Interventions for Children with Autism, National Research Council, April 12, 2000. Graduate School of Education and Information Studies, University of California at Los Angeles.

Kern, P., Wolery, M., \& Aldridge, D. (2007). Use of songs to promote independence in morning greeting routines for young children with autism. Journal of autism and developmental disorders, 37(7), 1264-1271.

Kim, J., Wigram, T., \& Gold, C. (2008). The effects of improvisational music therapy on joint attention behaviors in autistic children: a randomized controlled study. Journal of autism and developmental disorders, 38(9), 1758.

Krikeli V, Michailidis A, Klavdianou N. (2010). Communication Improvement through Music: The Case of Children with Developmental Disabilities. International Journal Of Special Education [serial online]. January 1, 2010;25(1):1-9. Available from: ERIC, Ipswich, MA. Accessed October 21, 2017.

Mace, F. C., Hock, M. L., Lalli, J. S., West, B. J., Belfiore, P., Pinter, E., \& Brown, D. K. (1988). Behavioral momentum in the treatment of noncompliance. Journal of Applied Behavior Analysis, 21(2), 123-141.

National Research Council. (2001). Educating children with autism. National Academies Press.

Nova Scotia Department of Education and Early Childhood Development, (2016). The Program Planning Process: A Guide for Parents and Guardians, Province of Nova Scotia.

Orr, T. J., Myles, B. S., \& Carlson, J. K. (1998). The impact of rhythmic entrainment on a person with autism. Focus on Autism and Other Developmental Disabilities, 13(3), 163-166.

Pelayo, J. I., \& Sanchez, C. S. (2013). Music Therapy with Autistic Children: A Multiple Case Study.

Sallows, G. O., \& Graupner, T. D. (2005). Intensive behavioral treatment for children with autism: Four-year outcome and predictors. American Journal on Mental Retardation, 110(6), 417-438.

Srinivasan, S. M., \& Bhat, A. N. (2013). A review of "music and movement" therapies for children with autism: embodied interventions for multisystem development. Frontiers in integrative neuroscience, 7.

Tomasello, M., \& Farrar, M. J. (1986). Joint attention and early language. Child development, 1454-1463.

Whipple, J. (2004). Music in intervention for children and adolescents with autism: A meta-analysis. Journal of music therapy, 41(2), 90-106.

Wimpory, D., \& Chadwick, P. (1995). Brief Report: Musical Interaction Therapy for Children with Autism: An Evaluative Case Study with Two-Year Follow-Up. Journal Of Autism \& Developmental Disorders, 25(5), 541.

Yeaw, J. A. (2001, August 1). Music Therapy with Children: A Review of Clinical Utility and Application to Special Populations. 